\title{
Gestantes no contexto da pandemia da Covid-19: reflexôes e desafios
}

I ${ }^{1}$ Fernanda Matheus Estrela, ${ }^{2}$ Keile Kemyly Assis da Silva,

${ }^{3}$ Moniky Araújo da Cruz, ${ }^{4}$ Nadirlene Pereira Gomes I

${ }^{1}$ Universidade Estadual de Feira de Santana. Feira de Santana-BA, Brasil (nanmatheus@yahoo.com.br). ORCID: 0000-0001-7501-6187
${ }^{2}$ Universidade Federal da Bahia. Salvador-BA, Brasil (keilekemylyassis@hotmail.com). ORCID: 0000-0002-1186-7502
${ }^{3}$ Universidade Federal da Bahia. Salvador-BA, Brasil (monikyac@hotmail.com). ORCID: 0000-0003-2955-5408
${ }^{4}$ Universidade Federal da Bahia. Salvador-BA, Brasil (nadirlenegomes@hotmail.com). ORCID: 0000-0002-6043-3997
Recebido em: 21/04/2020
Aprovado em: 25/04/2020
Revisado em: 28/04/2020

DOI: http://dx.doi.org/10.1590/S0103-73312020300215

O novo coronavírus, SARS-COV-2, agente etiológico da Covid-19, tem se propagado no mundo inteiro de maneira rápida, vulnerabilizando, dentre outros grupos, as gestantes. Diante das complicações para a gestação e o feto, faz-se necessário refletir sobre o estar gestante em tempos de pandemia da Covid-19 e a importância do cuidado profissional, sobretudo de enfermeiras, a fim de superar os inúmeros desafios que permeiam esse contexto.

A gestação é um período com diversas alterações fisiológicas, e esse público, durante as infecções causadas pelos vírus SARS-CoV, influenza H1N1 e MERSCoV, ocorridas em 2002, 2009 e 2012, respectivamente, apresentou complicaçôes diversas, como febre, tosse e dispneia (ALFARAJ; AL-TAWFIQ; MEMISH, 2019). Devido ao risco elevado de morbimortalidade, a Organização Mundial da Saúde (OMS) classificou as gestantes como grupo de risco para Covid-19. Na maioria dos infectados, os sintomas apresentados são leves, a exemplo de febre e tosse seca, porém, em mulheres na segunda metade da gestação, há outros sintomas que podem aparecer com menor intensidade nas gestantes, como fadiga, dispneia, diarreia, congestão nasal 
e coriza. Algumas mulheres podem apresentar ainda complicaçóes mais graves, como a síndrome respiratória aguda grave (SARS) (ZAIGHAM; ANDERSSON, 2020).

Tendo em vista esse cenário, muitas mulheres têm receio dos problemas que possam ocorrer durante o período da gestaçáo e no momento do parto, como a possibilidade de transmissão vertical do vírus. Sobre isso, os estudos ainda não são conclusivos: há aqueles que sinalizam a possibilidade do aparecimento de sintomas semelhantes ao da mãe infectada no recém-nascido; e outros que referem à impossibilidade de rompimento da barreira placentária (HOFFMANN et al., 2020). Devido a todas essas informaçôes e incertezas da ciência sobre os possíveis riscos de infecção, é compreensível o medo que as mulheres têm. Por isso, é importante que elas estejam atentas às fake news, devendo verificar se as notícias proveem de fontes confiáveis.

Soma-se a isso o receio quanto à impossibilidade de escolher entre o parto normal ou cesárea. A literatura aponta que gestantes com infecção por Sars-Cov-2 e que evoluem para um quadro grave associado a uma comorbidade têm probabilidade aumentada de passar por um parto cesariano de emergência ou um parto prematuro, o que eleva o risco de morte materna e neonatal (LI et al., 2020). Mesmo diante de um cenário adverso, os direitos das gestantes devem ser respeitados, mas algumas maternidades e hospitais, como forma de prevenir a Covid-19, têm adotado o isolamento no momento do parto. Esta medida diz respeito à não permissão de um acompanhante antes, durante e após o parto, direito esse apoiado na Lei $n^{\circ}$ 11.108/2005, conhecida como Lei do Acompanhante.

Cabe destacar que essa companhia é essencial para fornecer um apoio para as mulheres, principalmente as mães de primeira viagem. Pesquisa brasileira aponta que a presença de uma pessoa conhecida pela gestante no parto é capaz de amenizar a dor, promover segurança, bem-estar emocional e físico (SOUZA; GUALDA 2016). Considerando os efeitos benéficos de um acompanhante, urge que sejam repensadas medidas voltadas para a transmissibilidade da Covid-19 que não reverberem em experiências negativas na vida da mulher.

Segundo o Ministério da Saúde (BRASIL, 2020a), o acompanhante pode estar presente durante o parto, mesmo que a mulher seja positiva para o Sars-Cov-2, com as seguintes ressalvas: não deve haver revezamentos e o visitante não deve pertencer a grupos de risco para Covid-19. De acordo com os protocolos de saúde, o parto normal pode ser realizado em mães infectadas, caso elas não apresentem nenhuma complicação (BRASIL, 2020b). É importante que os hospitais e 
maternidades reconheçam os direitos das gestantes para garantir um cuidado humanizado e seguro. Para isso, podem ser adotados protocolos de paramentação e outras estratégias de proteção e prevenção, de modo a evitar a infecção do vírus e assegurar os direitos das gestantes.

No período gestacional, além das intensas alterações hormonais, existem questôes relacionadas à maternagem, a qual é definida como proteção e cuidado dos filhos, de forma afetuosa e carinhosa (GRADVOHL; OSIS; MAKUCH, 2014), sendo desenvolvida ao longo da vida como próprio da mulher Deste modo, vivenciar a pandemia da Covid-19 e estar gestante, considerando não existir consenso entre os estudos acerca da associação de gravidade da doença a esse período da vida, se relaciona a sentimentos de medos e incertezas. É nesse contexto que as(os) profissionais, sobretudo de enfermagem, necessitam repensar sua atuação de modo a amenizar ou impedir os impactos da doença para o binômio mãe-filho. Além disso, requer que sejam pensadas estratégias de cuidado que acolham e proporcionem bem-estar às mulheres durante todo o período gravídico-puerperal.

A somatização é compreendida como sintomas físicos de origem emocional, que podem ter origem nos pensamentos disfuncionais e emoçóes fortes que abalam o sistema psíquico são revelados nas gestantes por repercussões expressas por cefaleia, sintomas gastrointestinais, além de questôes de ordem psicológicas, sendo que ambas predispóem e/ou intensificam a depressão pós-parto, que é muito comum em cerca de $25 \%$ das brasileiras (FIOCRUZ, 2016). Diante disso, a fim de auxiliar na redução de impactos sobre a saúde mental das gestantes, faz-se necessário que os(as) profissionais estejam atentos(as) aos sinais e sintomas mais comuns, que são: ansiedade, ataque de pânico, culpa, insônia, perda de apetite e falta de concentração (FIOCRUZ, 2016). O olhar sensível e a escuta qualificada são essenciais para reconhecer a mulher nessa situação e, a partir de então, encaminhar para uma equipe multiprofissional.

Levando-se em consideração esse contexto, é fundamental o papel das(os) enfermeiras(os) tanto na Atenção Primária à Saúde (APS), durante a consulta do prénatal ou puerperal, quanto na atenção hospitalar. Vale ressaltar que, no espaço da APS, além do que já é preconizado para o atendimento pré-natal, os cuidados à saúde da gestante devem incluir orientaçôes, desmistificação de algumas ideias preconcebidas e medidas preventivas contra a Covid-19, como a higiene das mãos e das superfícies, o 
distanciamento social e o uso e confecção de máscaras. Esses cuidados podem ocorrer em diversos espaços, como em grupos de gestantes e na sala de espera.

É importante destacar ainda que, devido às constantes mudanças que estáo ocorrendo na rede de saúde, os desafios que as enfermeiras estâo encontrando para gestão e assistência do cuidado estão cada vez maiores, sendo necessário o planejamento de novas estratégias para atender às demandas das gestantes. Algumas dessas estratégias são: reorganização do fluxo da rede; acompanhamentos e orientações virtuais; triagem de classificação de risco; e as consultas e procedimentos de rotina durante o pré-natal das gestantes com sintomas da síndrome gripal devem ser adiados por 14 dias (BRASIL, 2020b).

Percebe-se que, para os profissionais de saúde, surgem os novos desafios de acompanhar a gestante a partir de um plano de cuidado especial, assegurando o devido suporte social e institucional nesse momento tão delicado. Diante disso, importante que os(as) profissionais de saúde, especialmente os(as) enfermeiros(as), conheçam a sintomatologia da Covid-19 para que possam prevenir o agravo dessa enfermidade, intervindo antecipadamente por meio de orientaçôes e encaminhamentos necessários para cuidar da saúde da gestante e do feto.

\section{Referências}

ALFARAJ, S. H.; AL-TAWFIQ, J. A.; MEMISH, Z. A. Middle East Respiratory Syndrome Coronavirus (MERS-CoV) infection during pregnancy: Report of two cases \& review of the literature. Journal of Microbiology, Immunology, and Infection, v. 52, n. 3, p. 501-503, jun. 2019. Doi: https://dx.doi.org/10.1016\%2Fj.jmii.2018.04.005.

BRASIL. Lei no 11.108, de 07 de abril de 2005. Dispóe sobre acompanhamento durante o trabalho de parto, parto e pós-parto imediato. Disponível em: <http://www.planalto.gov.br/ ccivil_03/_Ato2004-2006/2005/Lei/L11108.htm>. Acesso em: 23 abr. 2020.

. Ministério da Saúde. Departamento de açôes programáticas estratégicas. Atenção às Gestantes no Contexto da Infecção COVID 19 causada pelo Novo Coronavirus (SARSCoV-2), Brasília, 08 abr. 2020b. Disponível em: <https://saude.mg.gov.br/images/noticias_e_ eventos/000_2020/mar_abr_maio/14-04_NOTA-TECNICA-N-72020_COSMU__08_04. pdf>. Acesso em: 19 abr. 2020.

. Ministério da Saúde. Fluxo de manejo clínico de gestantes na atençáo especializada. Eletrônica. [S. 1.], 2020a. Disponível em: <https://www.saude.gov.br/images/pdf/2020/ marco/20/Fluxo-de-manejo-clinico-de-gestantes.pdf>. Acesso em: 12 abr. 2020. 
FUNDAÇÃO OSWALDO CRUZ. Depressão pós-parto acomete mais de 25\% das mães no Brasil. Rio de Janeiro: Fiocruz, 2016. Disponível em: <https://portal.fiocruz.br/noticia/depressao-posparto-acomete-mais-de-25-das-maes-no-brasil>. Acesso em: 23 abr. 2020.

GRADVOHL, S. M. O.; OSIS, M. J. D.; MAKUCH, M.Y. Maternidade e formas de maternagem desde a idade média à atualidade. Pensando fam., v. 18, n.1, p. 55-62, 2014. Doi: http://pepsic.bvsalud.org/scielo.php?script=sci_arttext\&pid=S1679-494X2014000100006\&ln $\mathrm{g}=$ pt\&nrm=iso $>$. Acesso em: 28 abr. 2020.

HOFFMANN, M. et al. SARS-CoV-2 Cell Entry Depends on ACE2 and TMPRSS2 and Is Blocked by a Clinically Proven Protease Inhibitor. Cell, 2020. Doi: https://dx.doi. org/10.1016\%2Fj.cell.2020.02.052.

LI, N. et al. Maternal and neonatal outcomes of pregnant women with COVID-19 pneumonia: a case-control study. Clinical Infectious Diseases, [s. 1.], 30 mar. 2020. Doi: https:/doi.org/10.1093/ $\mathrm{cid} / \mathrm{ciaa} 352$.

SOUZA, R. R. K.; GUALDA, D. M. R. A experiência da mulher e de seu acompanhante no parto em uma maternidade. Texto Contexto Enfer, v. 24, n. 1, e4080014, 2016. Doi: https://doi. org/10.1590/0104-0707201600004080014

ZAIGHAM, M.; ANDERSSON, O. Maternal and Perinatal Outcomes with Covid-19: a systematic review of 108 pregnancies. Acta Obstetricia Et Gynecologica Scandinavica, [s. 1.], 7 abr. 2020. Doi: https://doi.org/10.1111/aogs.13867. 